E-MAIL CONTRIBUTIONS

\title{
Examine funding equity at NIH and NSF
}

\section{P. KAYLUND}

A great deal of this debate has focused on the early education of females and child rearing as factors that account for the low representation of females at high level positions in science.

The fact remains, however, that even if these issues are eliminated, there is still a wealth of evidence to suggest that additional barriers exist to female advancement in science. The Wenneras and Wold study (Nature 387, 341; 1997), the project access study (Who Succeeds in Science, the Gender Dimension Sonnert and Horton, Rutgers Press), recent developments at MIT and an analysis of budget allocation at NCI (Science 264, 340; 1994) all illustrate that some women who are already succeeding in science careers are subject to inequities in allocation of resources and peer review. The diminished job satisfaction and confidence that result from this have serious impact on the ability of senior women to serve as role models for or encourage younger women towards scientific careers

\section{How to address this issue}

1. Examine funding equity from federal and private agencies. There has been no comprehensive study to address if extramural programs funded by $\mathrm{NIH}$ or NSF show evidence of gender inequity. My personal experience and conversations with colleagues funded over the long term by NIH indicate that there may be gender inequity in duration and magnitude of funding rather than absolute success rate but an objective and large scale analysis is required to determine if this is correct. Reduced duration of funding for any group of scientists would have an immense impact on productivity and job satisfaction as this determines the frequency of competetive applications for renewed research funding at intervals from three to five years. If inequities exist, something can be done about them If they don't, this would give reassurance to the female scientific community.

2. Adequate child care and special programs that take into account the impact of interrupted career on progress/tenure are certainly approaches to assist all scientists overcome barriers due to child rearing. Nevertheless, some well controlled studies, such as The Project Access study, concluded that having children was not a statistically significant factor in career outcome of their well controlled group of male and female scientists. As one who has raised two children while continuing science, I believe that we need some creative approaches to enable female scientists to have children and have relatively uninterrupted careers.

Many in main stream science simply cannot afford to take off 6 months or a year and have any realistic chance that this will not impede future productivity or career. Creative approaches such as resources to assist working from home, elimination of any non-essential duties for women during pregnancy and a post-partum period, assistance with child care costs when attending scientific meetings or professionally necessary events, extra secretarial help, would all assist women to continue the more essential aspects of their job while engaged in the demands of motherhood.

3. Mentoring and networking are useful but maximal benefit will not be achieved if women primarily mentor or network with other women. Mentors outside the home department are very valuable. Women often tend to discuss problems more openly than men and this can hurt the public evaluation of progress at important times such as tenure. It's really useful for all scientists to have a colleague outside your department or institution who can give an objective opinion without, later being asked to vote on your career 
advancement.

P. Kay Lund

Cell \& Molecular Physiology

University of North Carolina

Chapel Hill

USA

Nature @ Macmillan Publishers Ltd 1999 Registered No. 785998 England. 